\title{
Evaluation of the subsurface of an open dump area in the Amazon region (Pará, Brazil)
}

Marcia Leonor Oliveira de Sousa ${ }^{1}$ and Pedro Chira Oliva* ${ }^{1}$ Instituto de Estudos Costeiros (IECOS), Campus Bragança/UFPA, e-mail: chira@ufpa.br

Copyright 2019, SBGf - Sociedade Brasileira de Geofísica

This paper was prepared for presentation during the $16^{\text {th }}$ International Congress of the Brazilian Geophysical Society held in Rio de Janeiro, Brazil, 19-22 August 2019.

Contents of this paper were reviewed by the Technical Committee of the $16^{\text {th }}$ International Congress of the Brazilian Geophysical Society and do not necessarily represent any position of the SBGf, its officers or members. Electronic reproduction or storage of any part of this paper for commercial purposes without the written consent of the Brazilian Geophysical Society is prohibited.

\section{Abstract}

The emergence of cities and the growth of urban areas have contributed to the increase in the negative environmental impacts. A major concern is the impact caused by the improper disposal of municipal solid wastes in open dumps without any care or planning. These wastes cause the contamination of the groundwater, soil, the proliferation of disease-transmitting vectors, visual pollution and bad smell near to these sites. This preliminary study had as purpose the environmental characterization of the area of the open dump of the city of Tracuateua (Pará, Brazil). The Ground Penetrating Radar (GPR) electromagnetic tool was applied in the open dump with inadequately deposited solid wastes about a vast vegetation and near to water resources (i.e. streams). This method confirmed the environmental impact caused by the solid wastes from the open dump in the site with evidence of contamination of the local table water and neighboring areas.

\section{Introdução}

Um dos grandes problemas como consequência do crescimento da população e do desenvolvimento tecnológico e industrial é a geração e disposição dos resíduos sólidos. $O$ descarte destes resíduos é preocupante no Brasil, devido à cultura do consumismo exacerbado, que vem aumentando a quantidade e variedade de lixo evidenciando os impactos ambientais com a poluição cada vez mais notável, ocasionando de modo geral danos ao meio ambiente (Mucelin e Belline, 2008).

As implicações atuais estão voltadas para as questões de cunho ambiental, uma vez que o consumo exacerbado possa vir a acarretar implicações constantes relacionadas à destinação de resíduos sólidos de diversificadas origens, desde o orgânico até o químico, sem um cuidado em atender os parâmetros ambientais em saúde (FUNASA, 2002).

Grande parte dos resíduos sólidos, principalmente em países em desenvolvimento econômico lento e gradual traz ainda a predominância de pelo menos três modos para a destinação desses resíduos: a) em lixões considerados vazadouros a céu aberto, sem nenhum tratamento, b) em aterros controlados onde o lixo é depositado de modo controlado e coberto por uma camada de solo, c) em aterros sanitários para os solos que receberam tratamento prévio, como impermeabilização, respectivamente. Infelizmente a forma de disposição de resíduos sólidos urbanos (RSU) predominante no Brasil é em lixões a céu aberto.

A Associação Brasileira das Empresas de Saneamento Público e Resíduos Especiais (ABRELPE, 2016) constatou que das 71,3 milhões de toneladas de RSU geradas no Brasil em 2016, sete milhões de toneladas não foram coletadas e descartadas de forma adequada. No geral, $58,4 \%$ do RSU do país foi descartado em aterros sanitários, $24,2 \%$ em aterros controlados e $17,4 \%$ em lixões a céu aberto.

A Política Nacional de Resíduos Sólidos brasileira foi criada em 2010 e consiste em um programa de 20 anos, que deve ser atualizado em intervalos de quatro anos. No final de 2014 venceu o prazo proposto por essa política para a desativação dos lixões no Brasil. Esse prazo foi adiado para 2018, tendo em vista o não cumprimento dos principais objetivos desta política, como a eliminação e recuperação dos lixões existentes, associados a programas de inclusão social e à emancipação econômica da população dependente da recuperação artesanal e reciclagem de materiais (Brasil, 2010).

Em junho de 2017, foram identificados 2976 lixões no Brasil, que afetam a vida de 76,5 milhões de habitantes. Os custos governamentais estimados são superiores a 0,9 bilhões de dólares por ano para o desenvolvimento de medidas para compensar os impactos no meio ambiente e os problemas de saúde causados pela disposição inadequada dos RSU. Muitos municípios brasileiros simplesmente carecem de recursos financeiros ou de capacidade técnica para o manejo adequado de seus resíduos sólidos, criando uma barreira fundamental para a erradicação dos lixões (Brasil, 2017).

Os métodos geofísicos tem-se mostrado eficazes nos estudos de áreas contaminadas pela disposição descontrolada dos RSU. Existem diversos trabalhos que tem aplicado a geofísica nos estudos relacionados a contaminação da subsuperficie e agua subterrânea (Lago et al., 2006; Shiraiwa et al. 2000; Moura, 2002; Meju, 2000; Elis e Zuquette, 1997; Pires e Chira, 2014).

No caso do município de Tracuateua (NE do Pará), área escolhida para este estudo, existe um lixão a céu aberto localizado em uma área de vasta vegetação e próximo à recursos hídricos, tornando o local muito vulnerável à contaminação como consequência deste lixão. Isto traz inclusive uma relevância sob o aspecto ambiental para a preservação da qualidade dos recursos edáficos (Fonseca, 1999) que podem apresentar um índice de contaminação por chorume e por outros compostos nocivos que apresentando altas concentrações de metais pesados capazes de contaminar o solo e possivelmente os lençóis freáticos.

O presente estudo aplicou o método geofísico eletromagnético Ground Penetrating Radar (GPR) para 
investigar preliminarmente o impacto do lixão à ceu aberto da cidade de Tracuateua (Pará, Brasil) em relação ao meio ambiente.

\section{Material e métodos \\ Área de estudo}

A área de estudo (Figura 1) está localizada no município de Tracuateua (Pará, Brasil), onde existe um lixão a céu aberto. O referido município possui uma área de aproximadamente $936,13 \mathrm{~km}^{2}$ e está localizado na Mesorregião do Nordeste Paraense, Microrregião Bragantina, com coordenadas de $00^{\circ} 46^{\prime} 18^{\prime \prime}$ de Latitude Sul e $47^{\circ} 10^{\prime} 35^{\prime \prime}$ de Longitude Oeste.

O lixão a céu aberto localiza-se na prolongação da Avenida Mário Nogueira, distante aproximadamente $3 \mathrm{~km}$ do centro da cidade com percurso em estrada não pavimentada. Próximo a este lixão existem dois riachos localizados a $190 \mathrm{~m}$ (riacho 1) e $208 \mathrm{~m}$ (riacho 2) aproximadamente (Figura 1).

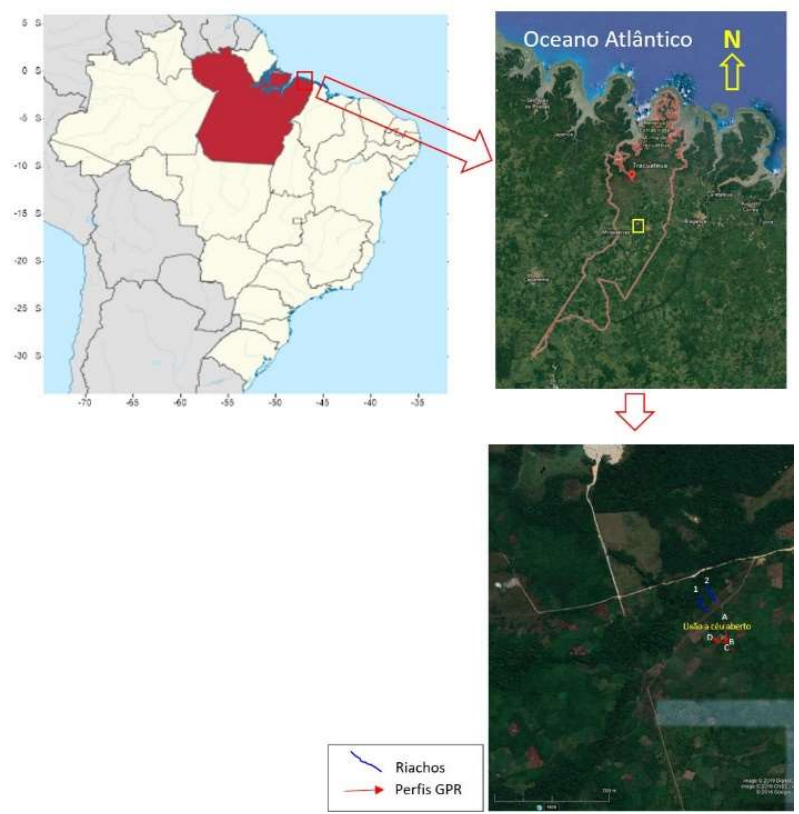

Figura 1. Área de estudo localizada no município de Tracuateua (Pará) com destaque para o lixão que fica próximo à cidade, vegetação da área e os riachos próximos ao mesmo. Modificado do Google Earth (2018).

\section{Levantamento de dados GPR}

Para o levantamento dos dados geofísicos foi utilizado o equipamento geofísico GPR da empresa GSSI SIR 3000 (Geophysical Survey Systems, Inc) (Figura 2). As coletas ocorreram nos períodos chuvoso (mês de fevereiro) e seco (mês de julho) de 2017. Foram utilizadas duas antenas: 200 e $400 \mathrm{MHz}$ com janelas temporais de 100, 150, 200 e 250 ns, respectivamente.

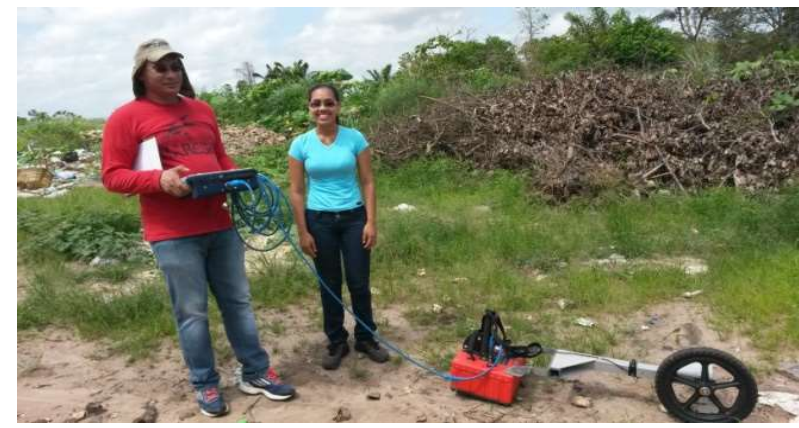

Figura 2. Equipamento GPR utilizado nas coletas dos dados geofísicos com destaque para a vegetação existente nas proximidades do lixão.

A utilização de uma janela temporal vai depender muito da profundidade interessada no estudo, podendo variar segundo o objetivo. A configuração fonte-receptor utilizado foi a common-offset (CO) ou afastamento comum. É

importante a predefinição da janela, pois ela é válida apenas para o trabalho, ou seja, as informações obtidas de acordo com a escala possuíram validade apenas para a mesma (Knight, 2001).

Os espaços compreendidos para geração do sinal foram de 10 metros nas linhas do levantamento geofísico, com arranjo monoestático, ou seja, apenas uma antena emite e recebe o sinal eletromagnético.

\section{Resultados}

Período chuvoso 2017

No período sazonal do tipo chuvoso foram levantadas doze (12) linhas de perfis GPR. Os perfis são referentes ao período chuvoso de 2017 (mês de fevereiro). A seguir apresentamos os principais perfis processados que resultaram deste levantamento (Figuras 3 a 6).

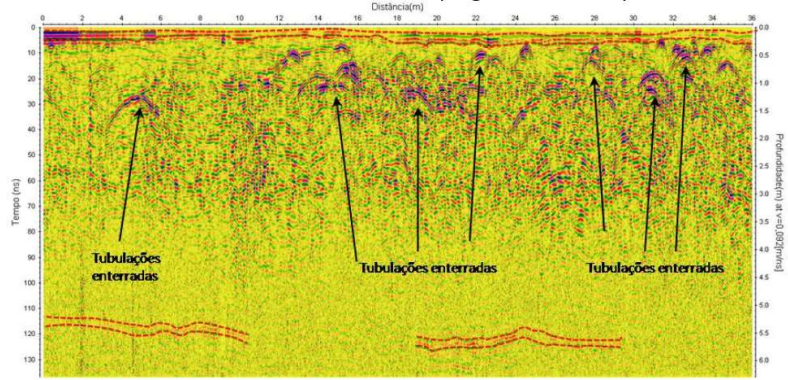

Figura 3. Radargrama do perfil $A B$ (fevereiro de 2017) com a antena de frequência de $400 \mathrm{MHz}$ e uma janela de tempo utilizada de 150 ns.

No perfil AB (Figura 3) foi identificado um forte refletor subhorizontal entre 0 e $0,3 \mathrm{~m}$ aproximadamente. Também foram idetificados vários eventos de reflexão em forma de hipérboles que poderiam estar relacionados a encanações ou tubulações enterradas. Na profundidade compreendida entre 5,3 e 5,8 m existe um forte refletor sub-horizontal que estaria indicando a presença de lençol freático. Esta identificação foi confirmada no trabalho de Santos (2018), que identificou a ocorrência do lençol freático nesta 
profundidade e também corroborada pelos cavadores de poços artesianos do local.

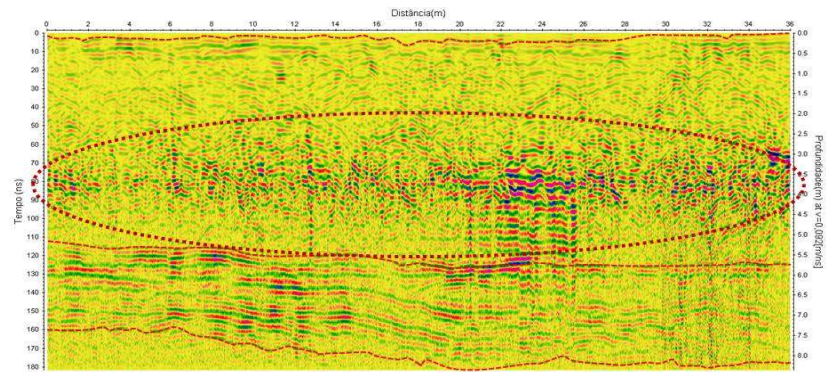

Figura 4. Radargrama do perfil $A B$ (fevereiro de 2017) com uma antena de frequência de $200 \mathrm{MHz}$ e uma janela de tempo utilizada de 200 ns.

Foi detectado na subsuperfície do anterior perfil (Figura 4), uma pluma de contaminação (delimitadas pela elipse pontilhada em vermelho).Neste mesmo perfil também foi identificado um pacote de camadas a uma profundidade compreendida entre 5,5 e 8 aproximadamente.

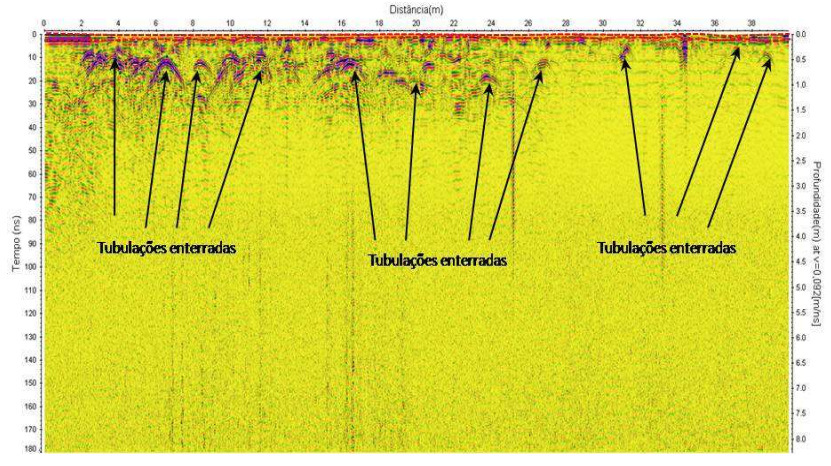

Figura 5. Radargrama do perfil $C D$ (fevereiro de 2017) com uma antena de frequência de $200 \mathrm{MHz}$ e uma janela de tempo utilizada de 200 ns.

Assim como no perfil anterior, no perfil CD (Figura 5) também foi detectada a ocorrência de vários eventos de reflexão em forma de hipérboles que poderiam estar relacionados à encanações ou tubulações enterradas. Neste perfil também foi identificado um forte refletor subhorizontal entre 5,5 e $6 \mathrm{~m}$ que corresponde ao mesmo lencol freático identificado e confirmado anteriormente.

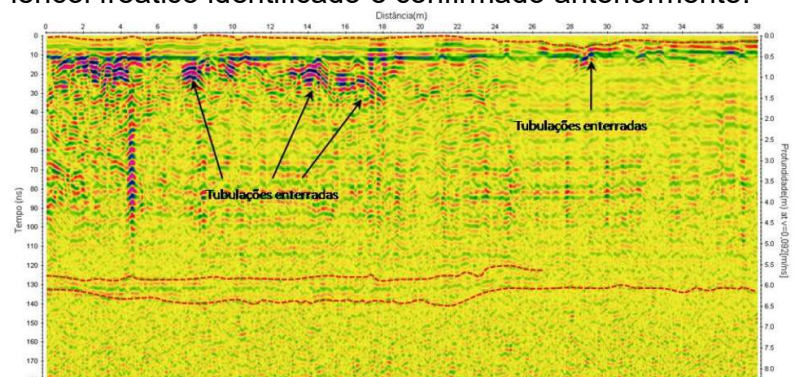

Figura 6. Radargrama do perfil CD (fevereiro de 2017) com uma antena de frequência de $400 \mathrm{MHz}$ e uma janela de tempo utilizada de 200 ns.
Similar ao comportamento do perfil $A B$ foi encontrado no perfil $C D$ da Figura $6 \mathrm{com}$ a identificação de um forte refletor sub-horizontal entre 0 e $0,3 \mathrm{~m}$, e a ocorrência entre 0 e $2 \mathrm{~m}$ de varios eventos de reflexão em forma de hipérbole que podem estar relacionados a encanações e tubulações enterradas.

Período seco (não chuvoso) 2017

Já no período sazonal não chuvoso (julho 2017) também foram levantadas doze (12) linhas de perfis GPR. A seguir apresentamos os principais perfis processados (Figuras 7 a 11).

No perfil $A B$ (Figura 7) foi identificado um forte refletor subhorizontal entre 0 e 0,3 m aproximadamente. Também foram detectados vários eventos de reflexão em forma de hipérboles que podem estar relacionados à encanações/tubulações enterradas principalmente entre as profundidades de 0 a $2 \mathrm{~m}$ e abaixo de $2 \mathrm{~m}$ aproximadamente (Figuras 7 à 11).

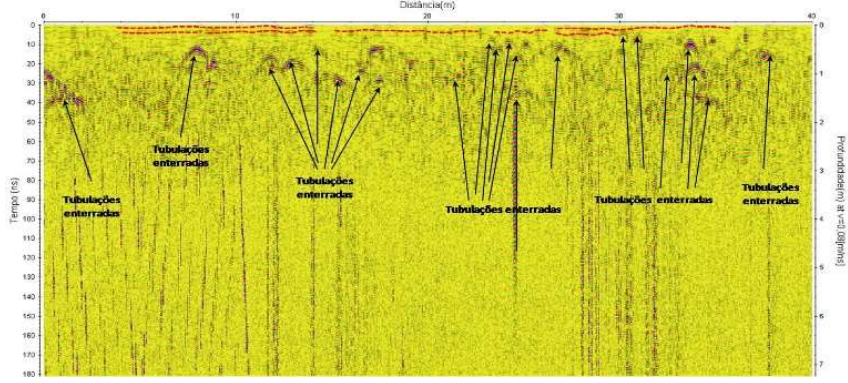

Figura 7. Radargrama do perfil $A B$ (julho de 2017) com uma antena de frequência de $400 \mathrm{MHz}$ e uma janela de tempo utilizada de $200 \mathrm{~ns}$.

Foi detectado um forte refletor sub-horizontal ocorrendo a uma profundidade aproximada de $5 \mathrm{~m}$ com um ângulo de mergulho de aproximadamente $3^{\circ}$ e que corresponde ao mesmo lençol freático detectado nos perfis anteriores (Figuras 8 e 9).

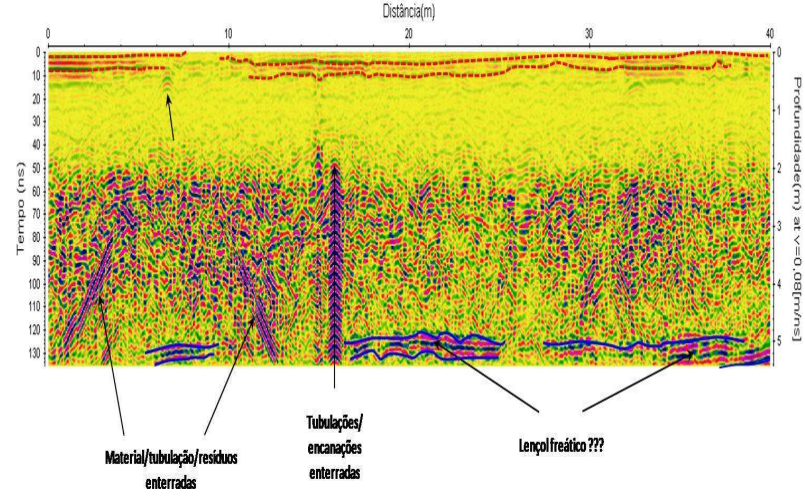

Figura 8. Radargrama do perfil $A B$ (julho de 2017) com uma antena de frequência de $200 \mathrm{MHz}$ e uma janela de tempo utilizada de 200 ns. 


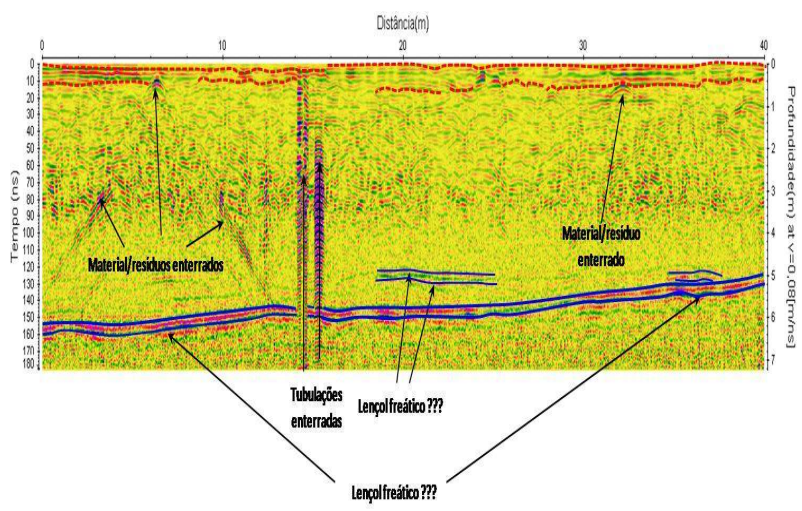

Figura 9. Radargrama do perfil $A B$ (julho de 2017) com uma antena de frequência de $200 \mathrm{MHz}$ e uma janela de tempo utilizada de 150 ns.

No que diz respeito ao perfil CD também foi identificado um refletor sub-horizontal próximo à superfície entre 0 e $0,25 \mathrm{~m}$ assim como a identificação de eventos de reflexão em forma de hipérboles que estariam indicando a ocorrência de material/resíduo enterrado entre 0 e $2 \mathrm{~m}$ de profundidade (Figuras 10 a 12). Neste perfil também foi confirmada a ocorrência do lençol freático detectado nos perfis anteriores (Figuras 11 e 12). Neste perfil foi detectado inclusive um pacote de camadas com um ângulo de mergulho de aproximadamente 35 a $36^{\circ}$ (Figura 11).

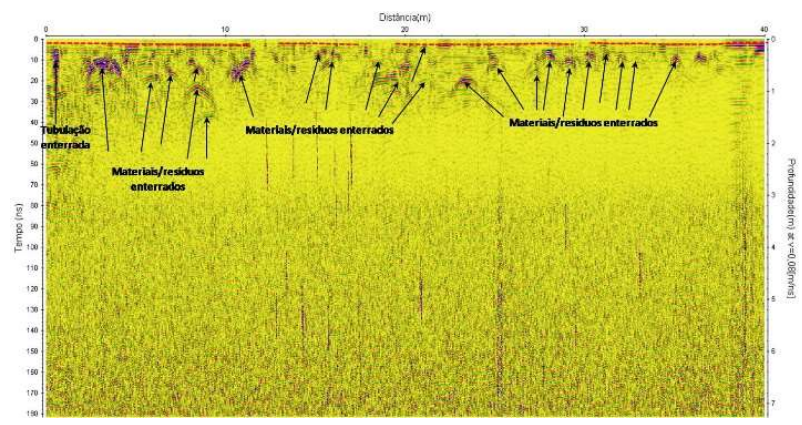

Figura 10. Radargrama do perfil $C D$ (julho de 2017) com uma antena de frequência de $400 \mathrm{MHz}$ e uma janela de tempo utilizada de 200 ns.

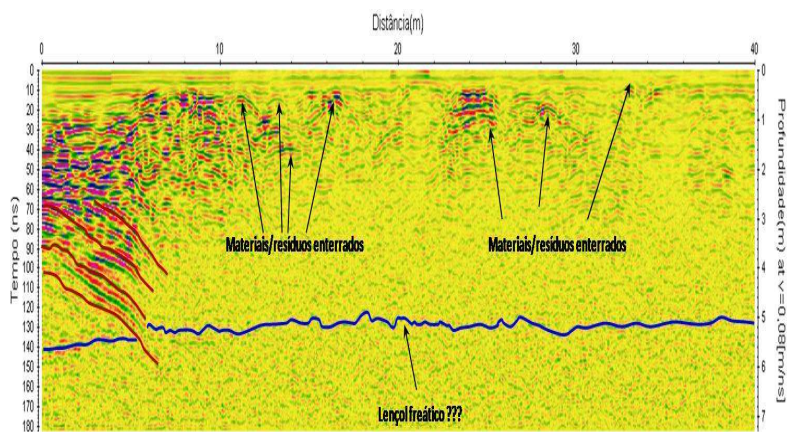

Figura 11. Radargrama do perfil $C D$ (julho de 2017) com uma antena de frequência de $200 \mathrm{MHz}$ e uma janela de tempo utilizada de 200 ns.

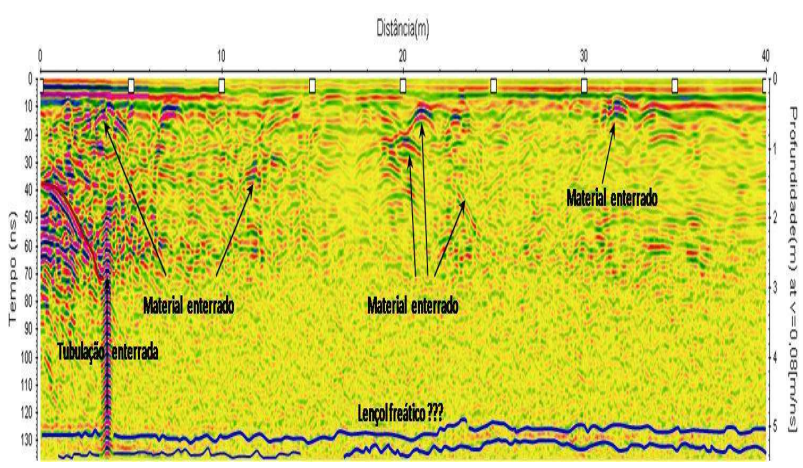

Figura 12. Radargrama do perfil CD (julho de 2017) com uma antena de frequência de $200 \mathrm{MHz}$ e uma janela de tempo utilizada de 150 ns.

\section{Conclusão}

O equipamento GPR permitiu caracterizar a área de influência do lixão na subsuperfície. Os radargramas gerados identificaram a presença de um refletor subhorizontal entre 0 e $0,3 \mathrm{~m}$ na subsuperfície.

Foi também detectada a presença de vários eventos de reflexão em forma de hipérboles que poderiam estar relacionados a encanações, materiais ou tubulações enterradas entre 0 e $2 \mathrm{~m}$ e abaixo de $2 \mathrm{~m}$ de profundidade aproximadamente. A camada sub-horizontal detectada na superfície indica que neste lixão existiram células com material de resíduos sólidos alí depositados sem nenhum critério e que depois foram compactados.

Também foi detectado um forte refletor sub-horizontal a uma profundidade de aproximadamente $5 \mathrm{~m}$ com um ângulo de mergulho compreendido entre $1^{\circ}$ e $3^{\circ}$ e que poderia estar relacionado com a ocorrência de um possível lençol freático. Os materiais/resíduos sólidos enterrados na subsuperficie estariam atingindo o lençol freático detectado.

\section{Referências}

ABRELPE - Brazilian Association of Public Cleaning and Special Waste Companies. Overview of Solid Waste in Brazil. Available in: http://www.abrelpe.org.br/panorama edicoes.cfm, 2016.

BRAZIL. Law no. 12305 of August 2, 2010. National Policy on Solid Waste. Available in: http://www.planalto.gov.br/ccivil 03/ ato20072010/2010/lei//12305.htm. , 2010.

BRAZIL. Roadmap for the closure of dumps - The most polluted places in the world. International Solid Waste Association (ISWA)/Association of Public Cleaning and Special Waste Companies (ABRELPE). Available in: www.iswa.org and www.abrelpe.org.br, 2017.

ELIS, V. R., ZUQUETTE, L. V.. Determinação da estrutura do aterro sanitário de Ribeirão Preto-SP através de métodos geoelétricos. Anais do $\mathrm{V}$ Congresso Internacional da Sociedade Brasileira de Geofísica, V1, São Paulo, SP, p. 417-420, 1997.

FONSECA, E. Iniciação ao estudo dos resíduos sólidos e da limpeza urbana. Editora União, 122 p, 1999. 
FUNASA. Relatório de gestão 2002. Coordenação de Gestão de Políticas Estratégicas

COGEP/CGPLA/DEPIN. Brasília: Ministério da Saúde, 2002.

GOOGLE EARTH. https://www.google.com/earth/, 2018.

KNIGHT, R. Ground penetrating radar for environmental applications. Annual Review of Earth and Planetary Sciences. 29: 22-255, 2001.

LAGO A.L, ELIS, V. R., GIACHETI H. L. Aplicação de métodos geofísicos em uma área de disposição de resíduos sólidos urbanos em Bauru-SP. Revista Brasileira de Geofísica, 24: 357-374, 2006.

MEJU, M. A. Geoelectrical investigation of old/abandoned, covered landfill sites in urban areas: model development with a genetic diagnosis approach. Journal of Applied Geophysics, 44: 115-150, 2000.

MOURA, H. P.. Emprego da eletrorresistividade e polarização induzida na caracterização geoelétrica de áreas de disposição de resíduos sólidos urbanos. Tese (Doutorado). Instituto de Geociências e Ciências Exatas, Universidade Estadual Paulista, Rio Claro, São Paulo, 223 p, 2002.

MUCELIN, C. A., BELLINI, M. Lixo e impactos ambientais perceptíveis no ecossistema urbano. Sociedade \& Natureza, Uberlândia, 20 (1): 111-124, 2008.

PIRES, D. B., CHIRA, P. Estudo ambiental do lixão urbano da cidade de Bragança (Pará) aplicando o Radar de Penetração no Solo (GPR). In: XVII Congresso Peruano de Geologia, 2014, Lima. XVII Congresso Peruano de Geologia "Alberto Benavides de la Quintana". Lima-Peru, 2014.

SANTOS, S. DA C. dos. Estudo da contaminação de águas subterrâneas no município de Tracuateua (Pará), através de métodos geofísicos e análises de água. Dissertação de Mestrado. Programa de Pós-graduação em Biologia Ambiental/IECOS/UFPA, 110 p, 2018.

SHIRAIWA, S., LISOVSKY, S. P., ELIS, V. R., PORSANI, J. L., BORGES, W. R. Estudos geofísicos integrados no lixão de Cuiabá, MT, Brasil- Resultados preliminares. Revista Brasileira de Geofísica, Cuiabá, 20, 182-186, 2002. 